\title{
ALGUNAS OBSERVACIONES SOBRE EL BLANQUEO IMPRUDENTE DE CAPITALES (ASPECTOS DOCTRINALES Y JURISPRUDENCIALES)
}

\section{Eduardo A. Fabián Caparrós}

Doctor en Derecho de la Universidad de Salamanca (España), Licenciado en Derecho, Universidad de Salamanca (España) Profesor Titular de Derecho Penal Universidad de Salamanca (España).

E-mail: efc@usal.es

\begin{abstract}
Resumen
El presente texto centra su análisis en el blanqueo imprudente de capitales en las iniciativas supranacionales a partir de tres ejes temáticos, el primero referente a las estructuras del tipo imprudente de blanqueo en el Código Penal español, en este punto se plantea la problemática del delito imprudente, el conocimiento del origen de los bienes y la intención de ocultar los bienes a los responsables. En segundo lugar, el autor explica la responsabilidad sobre el deber del cuidado exigible de los bienes. Finalmente, se aborda en un tercer eje la definición del sujeto activo del delito a partir del blanqueo imprudente como delito especial y como delito común. El trabajo advierte la poca incorporación del delito culposo de blanqueo al ordenamiento español, en instrumentos internacionales y en otros ordenamientos.
\end{abstract}

\section{Palabras clave}

Blanqueo imprudente de capitales, delito imprudente, bienes, responsabilidad, delito especial y delito común.

\begin{abstract}
The present paper focus its analysis on the imprudent money laundering and the supranational initiatives about it, from three thematic perspectives. The first one refers to the structures of money laundering crime in the Spanish Criminal Code, in this part it is explained the problem about money laundering crime, the knowledge of the origin of the capitals and the intention to hide the goods from the responsible. In second place, the author explains the responsability about the demandable duty of care after the goods. Finally, on the third place the definition of the active subject of the crime is approached from the perspective of money laundering as a special crime and ordinary crime. This paper reminds the lack of incorporation of norms about negligent money laundering crime in Spain, international instruments and other regulations.
\end{abstract}

\section{Key Words}

Money laundering, reckless, reckless crime, property, liability, crime and crime particularly common. 

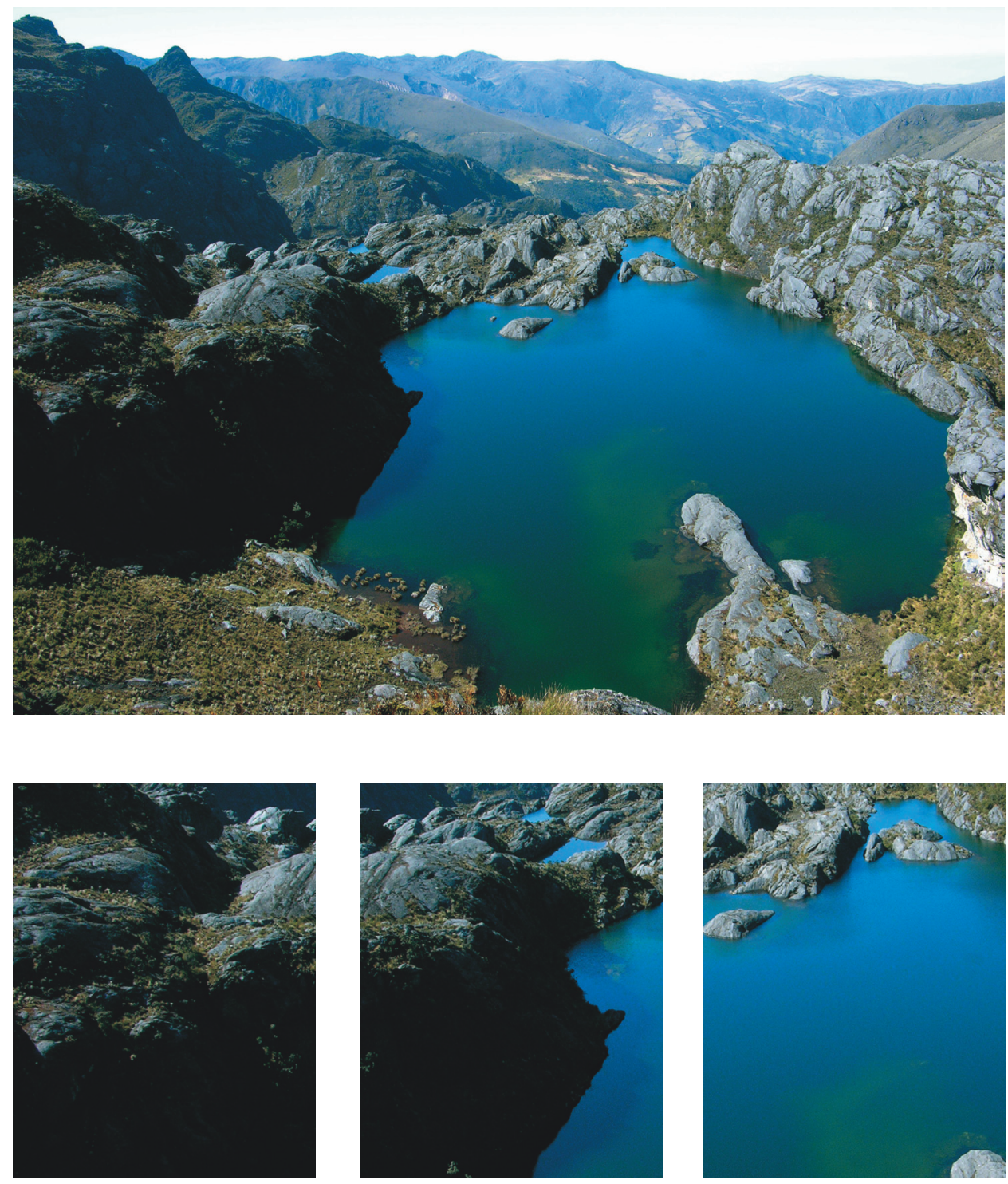

Laguna "La Pintada" 


\section{ALGUNAS OBSERVACIONES SOBRE EL BLANQUEO IMPRUDENTE DE CAPITALES (ASPECTOS DOCTRINALES Y JURISPRUDENCIALES) ${ }^{(*)}$}

Eduardo A. Fabián Caparrós

\section{Introducción}

Desde la entrada en vigor de nuestro Código Penal de $1995^{1}$, la regulación del delito de blanqueo de capitales se ha reformado en dos ocasiones. La primera, por obra de la Ley Orgánica 15/2003², amplió el cuadro de infracciones determinantes a cualquier hecho tipificado como delito -en su redacción original sólo se refería a los delitos graves- y retocó algunos otros aspectos con objeto de incrementar las sanciones. La segunda, producida por la reciente Ley Orgánica 5/2010 3 , ha afectado a varios aspectos de entre los que cabe destacar la ampliación de las conductas punibles, incluida la expresa tipificación del autoblanqueo -esto es, el que se produce cuando quien legaliza los bienes es el mismo sujeto que antes los ha obtenido participando en la infracción determinante-, la agravación de la pena cuando los bienes procedan de

(*) Este trabajo se enmarca en el Proyecto de Investigación "El blanqueo de capitales en el marco de la moderna delincuencia económica y la financiación del terrorismo", financiado por el Ministerio de Ciencia e Innovación del Gobierno de España (DER2009-13351) y en el Proyecto de Investigación "Corrupción, fraude y delincuencia económica: vías de integración jurídica desde las experiencias europea e iberoamericana”, financiado por la Consejería de Educación de la Junta de Castilla y León (SA033A10-1).

1 Ley Orgánica 10/1995, de 23 de noviembre, del Código Penal (BOE No. 281, de 24 de noviembre, pp. 33987 y ss.).

2 Ley Orgánica 15/2003, de 25 de noviembre, por la que se modifica la Ley Orgánica 10/1995, de 23 de noviembre, del Código Penal (BOE No.283, de 26 de noviembre, pp. 41842 y ss.).

3 Ley Orgánica 5/2010, de 22 de junio, por la que se modifica la Ley Orgánica 10/1995, de 23 de noviembre, del Código Penal (BOE No.152, de 23 de junio, pp. 54811 y ss.). 
actos de corrupción o de delitos contra la ordenación del territorio, $\mathrm{y}$, finalmente, la modificación de la propia rúbrica del Capítulo en el que se aloja este delito, que por fin descarta el artificioso apelativo de "conducta afín a la receptación" para pasar a denominarse, simple y llanamente, "blanqueo de capitales".

Realmente, hemos asistido a bastantes cambios normativos a lo largo de los últimos años que han afectado a esta materia. Más allá de los aspectos penales, nuestro Parlamento también ha aprobado recientemente la nueva Ley 10/2010, de prevención del blanqueo de capitales y de la financiación del terrorismo ${ }^{4}$, a la que luego me referiré con más detenimiento. Sin embargo, si se regresa al terreno criminal, ha habido otros aspectos que, aunque resulten doctrinal y jurisprudencialmente controvertidos, no han sido revisados hasta la fecha por el legislador.

Uno de esos asuntos conflictivos es el relativo al delito imprudente de blanqueo. Aunque sólo referido a las ganancias derivadas del narcotráfico, fue introducido hace casi dos décadas por la Ley Orgánica 8/1992 . Su incorporación al Código entonces vigente bien podría calificarse de rocambolesca ${ }^{6}$. Con todo, sus líneas básicas se

4 Ley 10/2010, de 28 de abril, de prevención del blanqueo de capitales y de la financiación del terrorismo (BOE No. 103, de 29 de abril, pp. 37458 y ss.). Esta norma es el resultado de la transposición de la Directiva 2005/60/CE, del Parlamento Europeo y del Consejo, de 26 de octubre de 2005, relativa a la prevención de la utilización del sistema financiero para el blanqueo de capitales y para la financiación del terrorismo (DOUE No. L 309, de 25 de noviembre, pp. 15 y ss.) y de la Directiva 2006/70/CE, de la Comisión, de 1 de agosto de 2006, por la que se establecen disposiciones de aplicación de la Directiva 2005/60/CE del Parlamento Europeo y del Consejo en lo relativo a la definición de "personas del medio político" y los procedimientos técnicos aplicables en los procedimientos simplificados de diligencia debida con respecto al cliente así como en lo que atañe a la exención por razones de actividad financiera ocasional o muy limitada (DOUE No. L 214, de 4 de agosto, pp. 29 y ss.). Como España no transpuso las citadas Directivas dentro del plazo en ellas establecido — 15 de diciembre de 2007-, nuestro país fue condenado por la Corte de Luxemburgo por Sentencia de 1 de octubre de 2009 (Asunto C-502/08, DOUE No. C 282, de 21 de noviembre, p. 13) y por Sentencia de 24 de septiembre de 2009 (Asunto C-504/08, DOUE No. C 282, de 21 de noviembre, p. 14).

5 Ley Orgánica 8/1992, de 23 de diciembre, de modificación del Código Penal y de la Ley de Enjuiciamiento Criminal en materia de tráfico de drogas (BOE No. 308, de 24 de diciembre de 1992, pp. 43861 y ss.).

6 El Grupo Parlamentario Izquierda Unida-Iniciativa per Catalunya propuso como enmienda No. 16 que el delito de tráfico de precursores, que entonces también se tramitaba, se previera en forma imprudente (Proyecto de Ley 121/000101, Orgánica de modificación del Código Penal y de la Ley de Enjuiciamiento Criminal en materia de tráfico de drogas, BOCG de 6 de octubre de 1992, Congreso de los Diputados, IV Legislatura, Serie A, No. 101-4, pp. 13 y 14). En el debate celebrado en el Pleno de la Cámara Baja sobre las modificaciones al Proyecto, el Grupo Socialista defendió una enmienda transaccional que, finalmente aprobada con el voto afirmativo de los 298 Diputados presentes en ese momento, transformó el pretendido delito culposo de tráfico de precursores en un delito imprudente de blanqueo de capitales derivados del narcotráfico (BOCG de 12 de noviembre de 1992, Congreso de los Diputados, IV Legislatura, Pleno y Diputación Permanente, No.227, p. 11267). Sobre esta cuestión, vid. FABIÁN CAPARRÓS, Eduardo A.:

“Consideraciones de urgencia sobre la Ley Orgánica 8/1992, de 23 de diciembre, de modificación del Código Penal y de la Ley de Enjuiciamiento Criminal en materia de tráfico de drogas", Anuario de Derecho Penal y Ciencias Penales, tomo XLVI (1993), p. 607. 
trasladaron al texto de 1995, en el que hoy, mutatis mutandis, se mantiene inalterado en su art. 301.3:

"Si los hechos se realizasen por imprudencia grave, la pena será de prisión de seis meses a dos años y multa del tanto al triplo".

En su aparente simplicidad, esta figura delictiva alberga una colección de problemas, muchos de ellos pendientes de resolver. Además, se trata de una infracción poco frecuente en el Derecho comparado ${ }^{7}$ cuya propia existencia, como detallaré más adelante, ha sido duramente criticada. A mi juicio, bien merece que se le dediquen unas cuantas páginas a su estudio.

\section{EI delito imprudente de blanqueo de capitales en las iniciativas supranacionales}

A pesar de que el blanqueo de capitales sea una de los fenómenos criminales que más atención ha merecido por parte de la Comunidad Internacional, llama la atención que su forma imprudente no haya tenido más que una escasa acogida en las iniciativas adoptadas hasta la fecha. Así lo han destacado tanto la doctrina ${ }^{8}$ como la jurisprudencia ${ }^{9}$, que advierten sobre el hecho de que el legislador español haya ido más allá de los compromisos asumidos.

Resulta significativo que esta figura no aparezca contemplada por ninguna de las Convenciones sobre la materia aprobadas en el ámbito de las Naciones Unidas. Ni la veterana Convención de Viena de $1988^{10}$, ni, más recientemente, la Convención

7 En nuestro entorno, se castigan ciertas formas de blanqueo imprudente, por ejemplo, en los apartados 2 y 4 del art. 505 del Código Penal belga (“(...) alors qu'ils connaissent ou devaient connaître l'origine de ces choses"), en el apartado 1 del art. 305bis del Código Penal suizo (“... valeurs patrimoniales dont ils savait ou devait présumer qu'ils provenaient d'un crime”) o en el apartado 5 del art. 261 del Código Penal alemán, aunque sólo respecto de las infracciones penales más graves ("Wer [...] leichtfertig nicht erkennt, dass der Gegenstand aus einer [...] rechtswidrigen Tat herrüht...”).

8 Entre otros, vid. ABEL SOUTO, Miguel: El blanqueo de dinero en la normativa internacional. Especial referencia a los aspectos penales, Universidad de Santiago de Compostela, Santiago de Compostela, 2002, pp. 177 y 178; BLANCO CORDERO, Isidoro: Responsabilidad penal de los empleados de banca por el blanqueo de capitales, Comares, Granada, 1999, pp. 181 y 182.

9 Vid. las SSTS 28/2010, de 28 de enero; 16/2009, de 27 de enero; 483/2007, de 4 de junio. También el ATS 790/2009, de 16 de abril.

10 Convención contra el tráfico ilícito de estupefacientes y sustancias sicotrópicas, hecha en Viena el 19 de diciembre de 1988 (Instrumento de ratificación por España, seguido del texto del Tratado, publicado en el BOE No. 270, de 10 de noviembre de 1990, pp. 33062 y ss.). 
de Palermo de $2000^{11}$ o la Convención de Mérida de $2003^{12}$ prevén nada al respecto, limitándose a pedir a las Partes que penalicen el blanqueo intencional respecto de una gama progresivamente amplia de delitos previos. Con todo, es cierto que en ellas se establece una cláusula abierta según la cual los Estados quedan autorizados a adoptar medidas complementarias más severas a las establecidas -como podría ser la tipificación del blanqueo imprudente- en el caso de que se consideren necesarias para cumplir con los fines establecidos en cada instrumento ${ }^{13}$.

Algo parecido cabe decir de los trabajos derivados del Grupo de Acción Financiera (FATF-GAFI) ${ }^{14}$, probablemente la institución de la que han derivado más resultados en la prevención y represión del fenómeno que nos ocupa. De hecho, su Recomendación No. 1 prevé que los países deben tipificar como delito el blanqueo de capitales, remitiéndose para su definición a lo previsto en la Convención de Viena y en la Convención de Palermo, antes citadas.

Diferente es el caso del Consejo de Europa. En este marco institucional, el art. 6. ${ }^{\circ}$ del Convenio de Estrasburgo de $1990^{15}$, tras exigir la tipificación del blanqueo intencional en su párrafo 1, preveía en el apartado a) de su párrafo 3 la posibilidad de que cada Parte también criminalice todas o parte de tales conductas dolosas en aquellos casos en los que el sujeto activo "debería haber presumido que los bienes eran producto de un delito". Ampliados los supuestos punibles, el párrafo 3 del art. 9. ${ }^{\circ}$ del Convenio de Varsovia de $2005^{16}$ también propone a los Estados que penalicen los hechos cuando su autor "albergaba sospechas de que los bienes eran producto de

11 Convención contra la delincuencia organizada transnacional, hecha en Nueva York 15 de noviembre de 2000 (Instrumento de ratificación por España, seguido del texto del Tratado, publicado en el BOE No. 233, de 29 de septiembre de 2003, pp. 35280 y ss.).

12 Convención contra la corrupción, hecha en Mérida el 31 de octubre de 2003 (Instrumento de ratificación por España, seguido del texto del Tratado, publicado en el BOE No. 171, de 19 de julio de 2006, pp. 27132 y ss.).

13 Así se ve en el art. 24 de la Convención de Viena, el art. 34.3 de la Convención de Palermo y en el art. 65.2 de la Convención de Mérida. Con carácter general, al hablar de un "estándar máximo abierto" —aunque quizá fuera más correcto hablar de un "estándar mínimo"_, vid. ABEL SOUTO, Miguel: El blanqueo de dinero..., Op. Cit., pp. 177 y 178.

14 Financial Action Task Force - Groupe d'Action Financière (FATF $\square$ GAFI), creado con motivo de la Cumbre de París del G $\square 7$ que tuvo lugar en 1989. La actuación del FATFGAFI gira en torno a la implementación y seguimiento de sus célebres Cuarenta Recomendaciones, aprobadas inicialmente en 1990 y cuya redacción vigente data de 2003. Tras los acontecimientos del 11 de septiembre de 2001, el FATF $\square$ GAFI aprobó otras Nueve Recomendaciones sobre financiación del terrorismo. Actualmente, el Grupo está integrado por 36 miembros, y a él pertenece España desde su fundación. Se puede obtener más información en su Web http://www.fatf $\square$ gafi.org.

15 Convenio relativo al blanqueo, seguimiento, embargo y decomiso de los productos del delito, hecho en Estrasburgo el 8 de noviembre de 1990 (Instrumento de ratificación, seguido del texto del Tratado, publicado en el BOE No. 252, de 21 de octubre de 1998, pp. 34713 y ss.).

16 Convenio relativo al blanqueo, seguimiento, embargo y decomiso de los productos del delito y a la financiación del terrorismo, hecho en Varsovia el 16 de mayo de 2005 (Instrumento de ratificación, seguido del texto del Tratado, publicado en el BOE No. 155, de 26 de junio de 2010, pp. 56174 y ss.). 
un delito". Por todo ello, los Tratados sobre blanqueo de capitales suscritos bajo los auspicios de esta Organización demuestran claramente su interés por el castigo de una amplia gama de formas de conocimiento atenuado sobre la procedencia ilícita de los bienes -no sobre cualquier otro elemento objetivo del tipo- para abarcar tanto los supuestos fronterizos entre la imprudencia consciente y el dolo eventual, como el desconocimiento negligente sin representación o, incluso, la mera sospecha ${ }^{17}$. Con todo, obsérvese que estas disposiciones no tienen carácter imperativo, sino sólo opcional, que constituye una simple orientación político-criminal cuyo cumplimiento no puede ser jurídicamente exigido a los Estados Parte ${ }^{18}$.

El Derecho Comunitario previo al Tratado de Lisboa nos ofreció una iniciativa sobre blanqueo de capitales adscrita al tercer pilar que, sin embargo, en nada afecta a su tipificación imprudente por parte de los Estados miembros. En efecto, la Decisión Marco 2001/500/JAI ${ }^{19}$ se limitó a incorporar al acervo común parte de los contenidos establecidos en el Convenio de Estrasburgo de 1990, que prohibían la formulación o mantenimiento de reserva alguna a una colección de disposiciones contenidas en la citada iniciativa del Consejo de Europa -por ejemplo, las relativas a la definición básica del delito de blanqueo-, pero sin incluir entre ellas a las referentes a su forma negligente. En el ámbito del primer pilar, el art. 1.1 de la vigente Directiva 2005/60/ $\mathrm{CE}^{20}$ exigió a los Estados miembros que el lavado de activos quedara prohibido en sus respectivos ordenamientos internos -sus limitaciones competenciales le impidieron pronunciarse sobre la naturaleza de la prohibición-, pero su art. 1.2, a la hora de definirlo, sólo quiso referirse a las formas dolosas.

Además de los compromisos contraídos por España, ya indicados, la inactividad de las instituciones internacionales respecto del castigo del blanqueo imprudente es la nota común. Como notable excepción, merece destacarse la postura asumida por la Organización de Estados Americanos a través del Reglamento Modelo sobre delitos

17 Así, vid. el epígrafe 97 del Explanatory Report al Convenio de Varsovia de 2005, disponible en http://conventions.coe.int/Treaty/EN/Reports/Html/198.htm.

18 Como destaca expresamente el epígrafe 98 del Explanatory Report al Convenio de Varsovia (cit.), “(...) el párrafo 3 es opcional. En consecuencia, con motivo del proceso de seguimiento previsto en el propio Convenio, no se podrá poner de relieve o censurar el hecho de que una Parte decida no adoptarlo en su Derecho interno".

19 Decisión Marco del Consejo, de 26 de junio de 2001, relativa al blanqueo de capitales, la identificación, seguimiento, embargo, incautación y decomiso de los instrumentos y productos del delito (DOCE No. L 182, de 5 de julio de 2001). El art. 5 de esta disposición derogó, reiterándolas, las previsiones comentadas en el texto contenidas en la Acción Común 98/699/JAI del Consejo, de 3 de diciembre de 1998, sobre la base del artículo K.3 del Tratado de la Unión Europea, relativa al blanqueo de capitales, la identificación, seguimiento, embargo, incautación y decomiso de los instrumentos y productos del delito (DOCE No. L 333, de 9 de diciembre de 1998).

20 Directiva 2005/60/CE, del Parlamento Europeo y del Consejo, de 26 de octubre de 2005, relativa a la prevención de la utilización del sistema financiero para el blanqueo de capitales y para la financiación de terrorismo (DOUE No. L 309, de 25 de noviembre de 2005). 
de lavado de activos ${ }^{21}$, aprobado en el marco de su Comisión Interamericana para el Control del Abuso de Drogas (CICAD), cuya redacción original data de 1992. En su redacción actual, el art. 2 define los delitos de blanqueo en sus tres primeros párrafos, prevé la tipificación de las conductas allí previstas cuando se cometen con dolo directo (a sabiendas) y dolo eventual (ignorancia intencional), pero también con imprudencia (debiendo saber), si bien sólo refiriéndola a la procedencia delictiva de los bienes. En todo caso, respecto de la comisión culposa, el propio Reglamento apunta que esta forma de imputación subjetiva queda por debajo de los estándares mínimos en el Derecho de algunos Estados miembros, motivo por el cual los Estados que la incorporen a su legislación "lo harán de una forma consistente con su respectivo ordenamiento jurídico".

En consecuencia, cabe concluir que el castigo del blanqueo imprudente no constituye una prioridad en el marco internacional. Estando sólo presente en contadas iniciativas, en ellas no se impone a los Estados la obligación de que tipifiquen esta conducta. Más bien, se limitan a proponerles que la asuman voluntariamente en sus respectivos ordenamientos penales y, además, restringida su relevancia al conocimiento del origen delictivo de los bienes, no al resto de elementos que integran el tipo doloso.

Simultáneamente, somos conscientes que -al menos, desde la perspectiva del respeto al principio de presunción de inocencia- el principal problema al que se enfrenta la acusación consiste en demostrar que el acusado de blanqueo intencional tuvo noticia del origen ilícito de los bienes, las citadas iniciativas, en general, reconocen la significación de la prueba de indicios para detectar tal conocimiento ${ }^{22}$. En tal sentido, parece que en la esfera supranacional se ha preferido abrir cauces procesales que permitan evidenciar la existencia de actos dolosos de blanqueo antes que relajar las exigencias subjetivas orientadas a imponer a los Estados la obligación de tipificar formas imprudentes.

21 Reglamento Modelo sobre delitos de lavado de activos relacionados con el tráfico ilícito de drogas y otros delitos graves, adoptado en junio de 1992 por la Asamblea General de la OEA con motivo de su XXII Periodo Ordinario de Sesiones, disponible en la Web de la CICAD http://www.cicad.oas. org. El Reglamento Modelo fue elaborado por un Grupo de Expertos que periódicamente actualiza sus contenidos.

22 El art. 3.3 de la Convención de Viena ya declaraba en 1988 que "el conocimiento, la intención o la finalidad requeridos como elementos de cualquiera de los delitos enunciados en el párrafo 1 del presente artículo [incluido el blanqueo de capitales] podrán inferirse de las circunstancias objetivas del caso". En similares términos se expresa el art. 6.2.f) de la Convención de Palermo, el art. 28 de la Convención de Mérida, el art. 6.2.c) del Convenio de Estrasburgo, el art. 9.2.c) del Convenio de Varsovia y otros. 


\section{La estructura del tipo imprudente de blanqueo en el Código Penal Español}

\section{A. La problemática configuración del delito imprudente de blanqueo}

En España, el delito de blanqueo imprudente de capitales es una figura dotada de una arquitectura relativamente extraña al sistema. Consagrada la técnica de crimina culposa en el art. 12 del Código Penal (las acciones u omisiones imprudentes sólo se castigarán cuando expresamente lo disponga la Ley), la mera existencia del art. 301.3 cumple formalmente con el citado mandato, pero traslada al operador jurídico la obligación de realizar un esfuerzo interpretativo semejante al que exigen las cláusulas generales que caracterizan a los sistemas de crimen culpce ${ }^{23}$. Como confirma la jurisprudencia, en este caso, "el legislador no crea un tipo distinto en el que se describan las correspondientes conductas basadas en la infracción del deber de diligencia" ${ }^{24}$, sino que opta por remitirse a las correspondientes figuras dolosas, lo que perjudica gravemente su autonomía y, en general, provoca ciertos problemas que trataré de abordar a continuación.

Para definir la conducta, el precepto alude tan sólo a "los hechos", refiriéndose con esta breve expresión a los actos intencionales contenidos en los apartados 1 y 2 del mismo artículo. Sin embargo, la carga subjetiva que contiene la redacción de tales apartados limita la posibilidad — si no la impide, a juicio de algunos - de que esos actos puedan cometerse culposamente. Como ha señalado reiteradamente nuestro Tribunal Supremo - pone con ello de relieve los dos grandes escollos de carácter subjetivo a los que se enfrenta la aplicación del art. 301.3—, esta figura

"no deja de presentar dificultades dogmáticas, por cuanto el blanqueo de capitales es delito esencialmente doloso que incorpora incluso el elemento subjetivo del injusto consistente en conocer la ilicita procedencia de los bienes y la intención de coadyuvar a su ocultación o transformación" 25 .

23 Vid. PALMA HERRERA, José Manuel: Los delitos de blanqueo de capitales, EDERSA, Madrid, 2000 , p. 589.

24 SSTS 28/2010, de 28 de enero; 483/2007, de 4 de junio.

25 SSTS 1257/2009, de 2 de diciembre; 1025/2009, de 22 de octubre; ATS 790/2009, de 16 de abril; 960/2008, de 26 de diciembre; 1034/2005, de 14 de septiembre (la cursiva indicada en el texto es mía). En otros pronunciamientos sobre la aplicabilidad del art. 301.3, el máximo órgano jurisdiccional también ha indicado, genéricamente, que "resulta cuestionable que los tipos penales que incorporan elementos subjetivos del injusto sean susceptibles de comisión imprudente" (SSTS 28/2010, de 28 de enero; 483/2007, de 4 de junio). 


\section{B. El conocimiento del origen de los bienes}

Comenzando por el primero de los problemas citados, es cierto que el hecho que todos los comportamientos intencionales de referencia exijan que el sujeto activo conozca el origen de los bienes ${ }^{26}$ no es fácil de conciliar con la idea de imprudencia. En este sentido, la STS de 17 de junio de 2005 destaca -desde una perspectiva causalista- que el art. 301.3 introduce "un factor culpabilístico que no deja de chocar y confrontarse con la redacción del texto, que se refiere reiteradamente a conductas realizadas a sabiendas del origen ilícito de los bienes" ${ }^{27}$. Por ello, no debe de extrañar que haya quienes piensen que el art. $301.3 \mathrm{es,} \mathrm{pura} \mathrm{y} \mathrm{simplemente,} \mathrm{inaplicable}{ }^{28}$.

A pesar de ello, mayoritariamente se tiende a realizar una interpretación correctora de la norma, coherente con la voluntad del legislador ${ }^{29}$, que salve su vigencia: por una parte, considerando que la remisión implícita que hace a los "hechos" contenidos en los apartados 1 y 2 del mismo artículo ha de entenderse en sentido naturalístico, no técnico-jurídico ${ }^{30}$; por otra, valorando que el conocimiento - defectuoso- de esa procedencia es, justamente, el elemento sobre el que reposa la negligencia. Dicho de otro modo, actuaría imprudentemente quien ignora el origen por haber incumplido el deber objetivo de cuidado que exige el art. 301.3. De hecho, en los últimos años se han dictado numerosas condenas por blanqueo negligente - a lo largo de este trabajo se citan numerosos ejemplos-, resultado al que siempre se ha llegado a partir de esta forma de ver las cosas.

26 Refiriéndose a los bienes, el apartado 1 indica que el sujeto debe actuar "sabiendo que éstos tienen su origen en una actividad delictiva", mientras que el apartado 2 exige que lo haga "a sabiendas de que proceden de alguno de los delitos expresados en el apartado anterior".

27 STS 924/2005, de 17 de junio.

28 Así, COBO DEL ROSAL, Manuel - ZABALA LÓPEZ-GÓMEZ, Carlos: Blanqueo de capitales. Abogados, procuradores y notarios, inversores, bancarios y empresarios. (Repercusión en las leyes españolas de las nuevas directivas de la Comunidad Europea), CESEJ, Madrid, 2005, pp. 101 y ss.; PALACIOS CRIADO, María Teresa: "Agentes intervinientes: el deber de colaboración. Especial mención de los Notarios", en PALACIOS CRIADO, María Teresa - FUENTES MARTÍNEZ, Jesús Julián (Dir..): Judicatura y Notariado ante los delitos económicos, Consejo General del Poder Judicial, Madrid, 2006, pp. 57-80.

29 Adviértase que la receptación - delito con el que el blanqueo comparte Capítulo en el Código de 1995, y para cuya existencia su art. 298 también requiere expresamente que el sujeto activo actúe con conocimiento del delito previo - no dispone de una figura imprudente paralela, por lo que el hecho de que sí se prevea para el blanqueo no debe ser intrascendente. Vid. QUINTERO OLIVARES, Gonzalo: "Sobre la ampliación del comiso y el blanqueo, y la incidencia en la receptación civil", Revista Electrónica de Ciencia Penal y Criminología, No. 12 (2010), p. 14. Reforzando esta postura, recuerdan que "el principio de legalidad, evidentemente, obliga a considerar la comisión imprudente del delito" las SSTS 1257/2009, de 2 de diciembre; 960/2008, de 26 de diciembre.

30 Vid., en tal sentido, VIDALES RODRÍGUEZ, Caty: Los delitos de receptación y legitimación de capitales en el Código Penal de 1995, Tirant lo Blanch, Valencia, 1997, pp. 129. Previamente, VIVES ANTÓN, Tomás S. (coord.): Comentarios al Código Penal de 1995, Tirant lo Blanch, Valencia, 1996, pp. 1466 y 1467. 
Que el art. 301.3 contenga una cláusula genérica para tipificar el blanqueo imprudente y que, además, sea tan parco en palabras -tan poco explícito- permitiría que la imprudencia no sólo se proyecte sobre el conocimiento del origen delictivo de los bienes, sino también sobre el resto de elementos que integran las figuras contenidas en los apartados 1 y 2 del mismo precepto, sobre la propia conducta ${ }^{31}$. En tal sentido, cabría imaginar que este precepto también castigue a quienes, por ejemplo, realizan sin querer -pero quebrantan su deber objetivo de cuidado- actos de conversión o transmisión de bienes de origen criminal; o también a quienes, siendo garantes, incumplan negligentemente sus deberes de supervisión que les sean inherentes y no eviten que se produzcan ${ }^{32}$.

Sin embargo, parece mayoritaria la opinión según la cual la negligencia punible no recae en este caso sobre la conducta en sí, sino sólo sobre el conocimiento del origen delictivo de los bienes ${ }^{33}$. Esta misma posición ha sido asumida uniformemente por la jurisprudencia, que se ha pronunciado reiteradamente y afirmado que "es claro que la imprudencia recae no sobre la forma en que se ejecuta el hecho, sino sobre el conocimiento de la naturaleza delictiva de los bienes receptados" ${ }^{34}$. Además, esta interpretación es coherente con lo establecido en el Convenio de Estrasburgo de 1990 y en el Convenio de Varsovia de 2005, que son los únicos instrumentos internacionales a los que se encuentra vinculada España en los que se hace referencia al castigo del blanqueo imprudente, aunque sea en los términos potestativos ya indicados en este mismo trabajo. Por último, conviene destacar que el hecho de que el art. 301.3, a diferencia del 301.1 y del 301.2, no prevea modulación penal alguna en referencia al origen de los bienes - recuérdese la agravación del castigo prevista en estos dos últimos preceptos para aquellos casos en los que los bienes provengan del tráfico

31 Considerando que el desconocimiento imprudente sobre el origen de los bienes cubre la mayoría de los casos enjuiciables a través del art. 301.3, pero no todos, vid. BLANCO CORDERO, Isidoro: Responsabilidad penal (...), Op. Cit., pp. 196 y 197. Indica que "sólo casos de ceguera lógica palmarios" podrían integrar una hipótesis de blanqueo imprudente en referencia a la realización de la conducta — aunque refiriéndose al viejo Código Penal—, QUERALT JIMÉNEZ, Joan J.: "La reforma penal y procesal en materia de tráfico de drogas", Actualidad Jurídica Aranzadi, No. 96 (1993), p. 3. En sentido parecido, respecto del nuevo texto, LÓPEZ GARRIDO, Diego - GARCÍA ARÁN, Mercedes: El Código Penal de 1995 y la voluntad del legislador, Tirant lo Blanch, Valencia, 1996, p. 148.

32 Previendo numerosos supuestos respecto de profesionales vinculados al sector financiero, vid. BLANCO CORDERO, Isidoro: El delito de blanqueo de capitales, Aranzadi, Pamplona, 2003 (2 ed.), pp. 411-412. En sentido parecido, PALMA HERRERA, José Manuel: Los delitos de blanqueo (...), Op. Cit. pp. 591-592.

33 Entre otros, vid. FABIÁn CAPARRÓS, Eduardo A.: El delito de blanqueo de capitales, Colex, Madrid, 1998, p. 421; GÓMEZ INIESTA, Diego J.: El delito de blanqueo de capitales en el Derecho español, Cedecs, Barcelona, 1996, p. 59; VIDALES RODRÍGUEZ, Caty: Los delitos de receptación..., Op. Cit. p. 129.

34 Vid. las SSTS 1257/2009, de 2 de diciembre; 1025/2009, de 22 de octubre; 16/2009, de 27 de enero; 960/2008, de 26 de diciembre; 1034/2005, de 14 de septiembre, etc. También el ATS 790/2009, de 16 de abril. 
de drogas, de los delitos de corrupción o de aquellos otros contra la ordenación del territorio - , induce a pensar que la carencia cognitiva que determine la imprudencia debe de vincularse, necesariamente, a tal aspecto ${ }^{35}$.

Realmente, entender así este polémico precepto permite, en cualquier caso, establecer una pauta hermenéutica de restricción que redundará en pro del principio de intervención mínima.

\section{La intención de ocultar los bienes o de favorecer a los responsables}

Que los tipos intencionales de referencia exijan al sujeto activo que conozca el origen delictivo de los bienes es un inconveniente que se puede salvar mediante una interpretación correctora. Sin embargo -y con ello entro a valorar el segundo de los problemas - , parece claro que el apartado 1 del art. 301 es absolutamente inidóneo para fundar una incriminación por blanqueo imprudente, dado que en él no sólo se exige tener noticia de esa procedencia, sino también que el sujeto actúe "para ocultar o encubrir su origen ilícito" o "para ayudar a la persona que ha participado en la infracción o infracciones a eludir las consecuencias legales de sus actos" 36 . Es obvio que las citadas expresiones implican una carga subjetiva incompatible con la comisión culposa e, incluso, con el dolo eventual.

En cualquier caso, la restricción de la imprudencia del art. 301.3 a los hechos contenidos en el art. 301.2 no supone, a mi juicio, una limitación sustancial que afecte al ámbito de lo punible. Como ya tuve ocasión de pronunciarme hace años ${ }^{37}$, la fenomenología del blanqueo de capitales me hace pensar que el art. 301.1 ("para ocultar o encubrir") no es una tentativa del art. 301.2 expresamente tipificada ("ocultación o encubrimiento"), ni tampoco un tipo alternativo que criminalice otra conducta sustancialmente diferente ${ }^{38}$. En consecuencia, podría decirse que todas las conductas previstas en el art. 301.2 — salvo las realizadas con dolo eventual o, precisamente, con imprudencia — podrían quedar incluidas en la ilimitada amplitud de la cláusula "o realice cualquier otro acto", en tanto no se estimen incluidas dentro de la colección de verbos "adquirir", "poseer", "utilizar", "convertir" o "transmitir", tal y como ha sido recientemente ampliada por la Ley Orgánica 5/2010.

35 Entre otros, vid. FABIÁN CAPARRÓS, Eduardo A.: El delito de blanqueo..., Op. Cit. p. 421.

36 Entre otros muchos, vid. FABIÁn CAPARRÓS, Eduardo A.: El delito de blanqueo..., Op. Cit. pp. 361 y 418; PALMA HERRERA, José Manuel: Los delitos de blanqueo(.), Op. Cit. p. 592; RUBIO LARA, Pedro Ángel: Parte especial del Derecho penal económico español. (Una aproximación al estado de la cuestión en la Doctrina y Jurisprudencia españolas), Dykinson, Madrid, 2006, p. 149.

37 FABIÁN CAPARRÓS, Eduardo A.: El delito de blanqueo (...), Op. Cit.pp. 412 y 413.

38 Salvo que, como ya ha hecho la jurisprudencia en algún caso (STS 457/2007, de 29 de mayo), la finalidad "para ayudar a la persona que haya participado en la infracción o infracciones a eludir las consecuencias legales de sus actos", prevista en el art. 301.1, se utilice para convertir casos que podrían haberse calificado fácilmente como supuestos de encubrimiento o falso testimonio en formas de blanqueo. 


\section{El deber de cuidado exigible}

Por exigencia expresa del art. 301.3, el blanqueo imprudente sólo se puede cometer si la negligencia es grave. En consecuencia, quedan desterrados del ámbito penal los hechos en los que intervenga imprudencia leve, descartándose también la aplicación de esta norma cuando se estime que la conducta del sujeto alcanza el dolo eventual, en cuyo caso procederá la aplicación de los arts. 301.1 o 301.2.

Como en tantas otras ocasiones, la calificación jurídica, mucho más fácil de resolver en el plano teórico, se complica cuando llegamos al terreno de la práctica. Tratándose de la frontera superior -la que distingue la imprudencia del dolo eventual-, la doctrina casi unánime ha aceptado su viabilidad en el marco de la tipificación del lavado de activos intencional. Es obvio que, desde una perspectiva político-criminal, no tiene sentido que se castigue la imprudencia, permaneciendo atípico el dolo eventual $^{39}$; y desde la óptica de la dogmática -y aunque no deba detenerme sobre este punto, por exceder del núcleo de este trabajo- existen diferentes vías que permiten su adopción. En algunos casos se ha rechazado respecto de las conductas previstas en el art. 301.1 en atención a la específica carga subjetiva que implican, admitiéndose al menos respecto del art. 301.2 $2^{40}$. Con todo, salvadas las dificultades de interpretación que puedan derivar de la expresa referencia a la necesidad de que el sujeto activo conozca el origen delictivo de los bienes, la mayoría de los autores han admitido su existencia, generalmente apoyándose en los criterios hermenéuticos establecidos en relación con el delito de receptación ${ }^{41}$. En esta misma línea, se ha defendido con razón que resultaría incoherente exigir certeza absoluta en la mente del agente para luego rebajar las exigencias de prueba y admitir que se deduce de datos objetivos indirectos - la cuantía de la operación, la aparente carencia de sentido económico, el empleo de grandes sumas en metálico y demás .- , es mucho más sensato argumentar que esos mismos datos objetivos permiten deducir que el autor previó la alta probabilidad de que los bienes procedían de actividades delictivas y, a pesar de ello, actuó ${ }^{42}$.

La jurisprudencia ha aceptado sin reservas el dolo eventual en los delitos de

39 Vid., por ejemplo, BLANCO CORDERO, Isidoro: El delito de blanqueo (...), Op. Cit. p. 387.

40 Así lo consideré hace años en FABIÁN CAPARRÓS, Eduardo A.: El delito de blanqueo (...), Op. Cit. pp. 397-398 y 415. En sentido similar, vid. GÓMEZ INIESTA, Diego J.: El delito de blanqueo..., Op. Cit. 1996, pp. 55-56.

41 Apoyándose con frecuencia en razonamientos ya elaborados con motivo del delito de receptación, vid., por ejemplo, BLANCO CORDERO, Isidoro: El delito de blanqueo (...), Op. Cit. pp. 384 y ss.; FABIÁN CAPARRÓS, Eduardo A.: El delito de blanqueo (...), Op. Cit.p. 397.

42 Respecto de la receptación, pero aplicando este criterio al blanqueo, vid. PÉREZ MANZANO, Mercedes: "El tipo subjetivo en los delitos de receptación y blanqueo de dinero", Cuadernos de Derecho Judicial, vol. I (1995), pp. 219 y ss. 
blanqueo desde hace bastante tiempo ${ }^{43}$. Con todo, una vez más, lo ha referido al conocimiento del origen delictivo de los bienes que constituyen el objeto material del delito, no a otros elementos objetivos del tipo. En tal sentido se pronunció el Tribunal Supremo con motivo de una Sentencia relativamente reciente dictada con ocasión del enjuiciamiento de un grupo organizado dedicado al tráfico internacional de cocaína, que parece ser deudora de los criterios ya acuñados desde hace bastante tiempo a propósito del delito de receptación:

"esta Sala abandonó, hace tiempo, una concepción que exigiera un dolo directo sobre el conocimiento de la ilícita procedencia de los bienes, afirmando la suficiencia del dolo eventual para su conformación. Consecuentemente puede afirmarse ese conocimiento cuando el autor ha podido representarse la posibilidad de la procedencia ilícita y actúa para ocultar o encubrir o ayudar a la persona que haya participado en la ilícita actividad, sin que deba exigirse una concreta calificación, siendo bastante un conocimiento genérico de la naturaleza delictiva del hecho sobre cuyos efectos se actúa. En otras palabras, basta con un conocimiento de las circunstancias del hecho y de su significado social" ${ }^{\prime 4}$.

Sentada la plena posibilidad de deducir responsabilidad a título de dolo eventual, lo que corresponde ahora es determinar cuándo procede esta calificación y en qué casos debe sólo apreciarse i mprudencia grave del art. 301.3. La distinción entre ambas categorías bien podría plantearse en términos clásicos, de acuerdo a los criterios del consentimiento y de la probabilidad. Restringido el análisis al problema de la determinación del origen de los bienes, cometería blanqueo doloso quien, previsto ex ante su origen delictivo, aceptara la realización de operaciones sobre los mismos teoría del consentimiento - o las realizara siendo consciente de que existen muchas posibilidades de que en efecto tengan ese origen ${ }^{45}$.

Con todo, tratándose del blanqueo de capitales, la interpretación de las normas es deudora de una construcción de origen anglosajón (willful blindness), aceptada por

43 Entre otras muchas, vid. las SSTS 801/2010, de 23 de septiembre; 483/2007, de 4 de junio; 457/2007, de 29 de mayo; 390/2007, de 26 de abril; 289/2006, de 15 de marzo; 202/2006, de 2 de marzo; 1070/2003, 22 de julio; 2545/2001, de 4 de enero, etc.

44 STS 483/2007, de 4 de junio, en la que también se citan las SSTS 1034/2005, de 14 de septiembre; 33/2005, de 19 de enero; 1113/2004, de 9 de octubre; 308/2004, de 12 de marzo; 1070/2003, de 22 de julio; 157/2003, de 5 de febrero; 1637/1999, de 10 de enero de 2000.

45 Respecto de las teorías diferenciadoras entre el dolo eventual y la imprudencia consciente, y sin ánimo de menospreciar la excelente y abundante doctrina al respecto que se ha publicado mucho más recientemente, me permito recordar el reconocido trabajo de GIMBERNAT ORDEIG, Enrique: "Acerca del dolo eventual", en su conocida recopilación Estudios de Derecho Penal, Tecnos, Madrid, 1999 (3a. ed.), pp. 240 y ss. 
nuestro Tribunal Supremo bajo la denominación "ignorancia deliberada"46. Como destaca la doctrina, numerosas resoluciones equiparan esta forma de obrar con la de quien lo hace bajo el concepto de dolo eventual, en la medida en que el sujeto "pretende desconocer la procedencia ilícita de los bienes, cuando constan elementos suficientes para deducirlo"

En el límite inferior de la responsabilidad, debe recordarse que la imprudencia que castiga el art. 301.3 es la grave, no la leve, que queda fuera del Código Penal. Distinguir entre ambas no es fácil; tanto es así que entre la doctrina española se ha llegado a defender que en este caso se infringe el principio de legalidad -por ausencia de taxatividad-, postulando por ello la inconstitucionalidad del precepto ${ }^{48}$. También la jurisprudencia se ha hecho eco de estas dificultades, afirmando que "no es fácil separar en estos casos lo grave (o temerario) de lo leve (o simple)" ${ }^{\prime 49}$, especialmente cuando se trata de particulares cuyos deberes de cuidado no se encuentran normativamente tasados, como sí ocurre con los sujetos obligados por la vigente Ley 10/2010, que vino a sustituir a la derogada Ley 19/1993. En general, se aprecia que la gravedad debe quedar motivada claramente en el fallo condenatorio, indicando claramente en qué punto concreto se produjo la infracción de ese quebrantamiento de la cautela debida y señalando cómo el acusado podría haber alcanzado en cada caso el conocimiento respecto de la procedencia delictiva de los bienes cuyo blanqueo realizó.

\section{Definición del Sujeto activo del delito}

\section{A Planteamiento del problema}

Una de las cuestiones más controvertidas sobre la regulación del delito de blanqueo imprudente es la relativa a la definición de su sujeto activo. Como veremos a continuación, no hay una doctrina dominante que permita establecer si nos encontramos ante un delito común o especial. A ello se une una jurisprudencia

46 Sobre esta construcción doctrinal, vid. RAGUÉS I VALLÈS, Ramón: La ignorancia deliberada en Derecho penal, Atelier, Barcelona, 2008. passim.

47 CALDERÓN CEREZO, Ángel - SAAVEDRA RUIZ, Juan (coords.): Delitos contra el orden socioeconómico, La Ley, Madrid, 2008, p. 407. Los autores citan, entre otras, las SSTS 390/2007, de 26 de abril; 797/2006, de 20 de julio. Me permito añadir las más recientes SSTS 961/2010, de 11 de noviembre; 374/2009, de 28 de enero.

48 Citando a Blanco Lozano, vid. BLANCO CORDERO, Isidoro: Responsabilidad penal..., Op. Cit.p. 187.

49 STS 957/2007, de 23 de noviembre, en la que se hace también referencia a la STS 1034/2005, de 14 de septiembre. 
que probablemente no merezca tal nombre, dado que tampoco ofrece criterios homogéneos de interpretación en sus -sin embargo- numerosos pronunciamientos ${ }^{50}$.

Definir el sujeto activo de un tipo delictivo corresponde al estudio de la vertiente objetiva del mismo. Sin embargo, como veremos a continuación, optar por una u otra solución conecta íntimamente con la idoneidad del agente para cumplir con su vertiente subjetiva en relación con su capacidad para conocer las situaciones de riesgo de afectación del bien jurídico protegido que, desde la posición social que en cada caso desempeñe, le son penalmente exigibles. A esta cuestión dedicaré las próximas líneas.

\section{B. El blanqueo imprudente como delito especial}

Los partidarios de la tesis del delito especial basan su postura sobre la inexigibilidad de un deber objetivo de cuidado a la generalidad de los ciudadanos en relación con la tutela del contenido material que da fundamento al art. 301.3 ${ }^{51}$. Quienes así piensan consideran que este delito sólo puede ser cometido por aquellas personas y entidades que estén sometidas a especiales deberes de vigilancia por la normativa administrativa sobre prevención del blanqueo de capitales -los denominados "sujetos obligados" enumerados en el art. 2. 'Ley 10/2010, de prevención del blanqueo de capitales y de la financiación del terrorismo ${ }^{52}$, que igualmente serían las únicas vinculadas a los deberes de cuidado que impone el delito de blanqueo imprudente. Con una argumentación similar, pero realizándolo desde la perspectiva opuesta, se

50 Recordemos que el apartado $6 .^{\circ}$ del artículo $1 .^{\circ}$ del Código Civil español define la jurisprudencia como "la doctrina que, de modo reiterado, establezca el Tribunal Supremo al interpretar la ley, la costumbre y los principios generales del Derecho", esto es, las fuentes del Derecho reconocidas en el apartado $1 .^{\circ}$ del mismo precepto. Siendo así, podrá afirmarse que, como queda demostrado en el presente trabajo, existe un número relevante de resoluciones de nuestro máximo órgano jurisdiccional sobre esta materia, pero, faltan criterios unitarios al respecto, no existe realmente una jurisprudencia sobre la misma. Denunciando esta falta de coherencia, COBO DEL ROSAL, Manuel - ZABALA LÓPEZ-GÓMEZ, Carlos: Blanqueo de capitales..., Op. Cit. p. 101. Reconociendo la existencia de pronunciamientos discrepantes emitidos por el Alto Tribunal, vid. la STS 960/2008, de 26 de diciembre.

51 BLANCO CORDERO, Isidoro: El delito de blanqueo..., Op. Cit. p. 416.

52 Refiriéndose a la entonces vigente Ley 19/1993, derogada por la nueva Ley 10/2010, aparentan defender esta postura, entre otros, BLANCO CORDERO, Isidoro: Responsabilidad penal..., Op. Cit. pp. 198 y 199; GÓMEZ INIESTA, Diego J.: El delito de blanqueo..., Op. Cit.1996, pp. 59 y 60; QUINTERO OLIVARES, Gonzalo: "De la receptación y otras conductas afines", en QUINTERO OLIVARES, Gonzalo (dir.): Comentarios al nuevo Código Penal, Thomson-Aranzadi, Navarra, 2005 (4. ${ }^{a}$ ed.), p. 1519; RUBIO LARA, Pedro Ángel: Parte especial del Derecho penal económico español (una aproximación al estado de la cuestión en la Doctrina y Jurisprudencia españolas), Dykinson, Madrid, 2006, p. 149; VIDALES RODRÍGUEZ, Caty: Los delitos de receptación..., Op. Cit. p. 127. 
ha llegado a afirmar que la interpretación como delito común del art. 301.3 haría que éste fuera inconstitucional, dado que en el marco de un Estado de Derecho sería inadmisible que se impusiera a todas las personas un deber de investigación y conocimiento de los movimientos económicos ajenos, así como de los posibles delitos que hayan cometido sus conciudadanos ${ }^{53}$. En términos menos radicales, también se ha defendido la conveniencia de apreciar el carácter especial de esta figura en cumplimiento del principio de intervención mínima ${ }^{54}$.

En consecuencia, como delito especial, el art. 301.3 sería una ley penal en blanco ${ }^{55}$ que se remitiría implícitamente a tales normas administrativas, toda vez que en ellastanto en la ya citada Ley 10/2010 como en las disposiciones reglamentarias que la desarrollan- es donde se describen las exigencias que competen a tales sujetos, esto es, la concreción del deber objetivo de cuidado al que se encuentran sometidos.

El carácter especial del delito de blanqueo imprudente también es defendido desde la óptica del principio de taxatividad. Como ya recordé anteriormente ${ }^{56}$, el legislador no describe la conducta que el sujeto activo debe de realizar para consumarlo. Por ello, se considera que es muy difícil distinguir en la práctica la frontera entre la imprudencia grave - punible- de la leve-atípica- cuando no existe una referencia normativa que establezca los criterios de cuidado exigible, esto es, en el caso de los sujetos no obligados, de los ciudadanos comunes y corrientes que son ajenos a la tantas veces aludida regulación administrativa sobre prevención del blanqueo de capitales ${ }^{57}$.

Trasladado el debate al ámbito jurisprudencial, las resoluciones judiciales que hasta hoy han estimado que el blanqueo culposo es un delito especial también han puesto de relieve la cualificada posición de los sujetos obligados y afirmar que "su comisión sólo estará al alcance de personas cuya conducta sea reprobable por la infracción de específicos deberes de cuidado que le sean exigibles legal o reglamentariamente, en consideración al desempeño de determinadas actividades con carácter profesional o

53 Respecto del delito de blanqueo imprudente previsto en el viejo Código Penal, BLANCO LOZANO, Carlos: "El blanqueo de capitales procedentes del tráfico de drogas en el ordenamiento penal español”, en COBO DEL ROSAL, Manuel (dir.): Comentarios a la legislación penal. Delitos contra la salud pública (reformas sobre tráfico de drogas, secreto de las comunicaciones y conducción de ciclomotores), EDERSA, Madrid, 1996, pp. 53 y ss.

54 BAJO FERNÁNDEZ, Miguel: "El desatinado delito del blanqueo de capitales", en BAJO FERNÁNDEZ, Miguel - BACIGALUPO SAGESSE, Silvina (eds.): Política criminal y blanqueo de capitales, Marcial Pons, Madrid, 2009, p. 18.

55 Así se pronuncia explícitamente la STS 483/2007, de 4 de junio, siguiendo la doctrina planteada en la STS 924/2005, de 17 de junio. Expresamente en contra, al rechazar los argumentos de la defensa, vid. la STS 960/2008, de 26 de diciembre.

56 Vid. supra, apartado III.A.) del presente trabajo.

57 BLANCO CORDERO, Isidoro: Responsabilidad penal..., Op. Cit.p. 187. 
funcionarial" 58 , hasta llegar a expresar la idea de que en estos casos los particulares quedarían suficientemente sancionados mediante la apertura de los correspondientes expedientes administrativos y el comiso de los bienes incautados ${ }^{59}$. Aunque no creo que se trate de un argumento especialmente convincente, en otros pronunciamientos se refuerza esta argumentación al apelar a la vigencia del art. 303, entendiéndose que este precepto

"da pie para establecer [...] que el legislador está pensando en una amplia gama de profesionales entre los que incluye a los empresarios, intermediarios en el sector financiero, facultativo, funcionario público, trabajador social, docente o educador en el ejercicio de su cargo" 60 .

A este "deber de diligencia intensificado que podría derivar en una auténtica negligencia profesional" 61 , el Tribunal Supremo añade otro argumento aparentemente vinculado al principio de seguridad jurídica. Así, la falta de una norma de referencia que regule la conducta exigible al común de los ciudadanos en este ámbito hace que respecto de ellos se requiera determinar "en qué punto concreto se produjo la infracción de ese deber de cuidado inherente siempre al concepto de imprudencia, es decir, ha de decirse qué es lo que podía haber hecho el acusado en estos casos de negligencia inexcusable, cómo podía haber alcanzado en este concreto ese conocimiento de la procedencia delictiva de esos bienes cuyo blanqueo se ha realizado" ${ }^{\prime 2}$. Como señala el alto Tribunal en otra resolución "problemático será en las actividades sociales en que no se han establecido normas de cuidado, o en las situaciones atípicas, determinar

58 Sobre la argumentación originalmente contenida en la STS 924/2005, de 17 de junio, luego asumida por la STS 94/2006, de 10 de febrero, el fragmento transcrito se ha tomado de las SSTS 16/2009, de 27 de enero; 483/2007, de 4 de junio.

59 STS 924/2005, de 17 de junio.

60 SSTS 94/2006, de 10 de febrero; 924/2005, de 17 de junio. Afortunadamente, no parece que el Tribunal Supremo haya vuelto a apelar en este sentido a la mens legislatoris después de estas resoluciones que he citado. A mi juicio, invocar aquí el art. 303 es un argumento poco oportuno: primero, porque los profesionales cuya responsabilidad se agrava en este precepto no coinciden con los relacionados en la normativa administrativa sobre prevención del blanqueo de capitales; segundo, porque el art. 303 constituye un claro vestigio de la subordinación que el lavado de activos tuvo en sus orígenes con los delitos de narcotráfico, situación inaceptable en la actualidad. Transcurridos más de quince años desde la publicación del nuevo Código Penal y aprobadas más de una veintena de reformas sobre su texto, sorprende comprobar que este precepto - copia prácticamente literal del art. 372, dentro de los delitos contra la salud pública - mantenga imperturbada su vigencia y prevea la imposición de una pena complementaria de inhabilitación a ciertos profesionales trabajadores sociales, docentes, educadores, médicos, psicólogos, enfermeros, veterinarios, farmacéuticos y otros .- cuyo desempeño es totalmente ajeno a la fenomenología del blanqueo de capitales, así como a su contenido material. Ya me pronuncié hace casi veinte años en este mismo sentido respecto del art. 344 bis c) del viejo Código Penal en relación con el delito de blanqueo en FABIÁN CAPARRÓS, Eduardo A.: “Consideraciones de urgencia (...) Op. Cit ,.p. 614.

61 STS 924/2005, de 17 de junio.

62 STS 959/2007, de 23 de noviembre. Amparándose en la amplia literalidad del precepto, esta resolución no descarta totalmente la posibilidad de que el art. 301.3 pueda aplicarse a particulares, pero viene a hacerlo en términos prácticos - fundamentando así la absolución de los acusados, previamente condenados en la instancia - a partir de los argumentos indicados en el texto. 
el cuidado objetivamente debido mediante el criterio de la conducta que observaría en esa situación concreta una persona inteligente y sensata de la misma profesión o círculo social, y si es en el ámbito de los negocios cuál sería la actitud con respeto a la realización de operaciones comerciales extrañas" ${ }^{63}$. Resumiendo - y también conectando con el criterio doctrinal antes citado que apelaba al cumplimiento del principio de taxatividad-, según esta línea jurisprudencial, sin dolo, tal vez pueda identificarse un cierto grado de negligencia en la actuación de los particulares, pero resulta extremadamente difícil determinar que esa imprudencia alcanza el rango de grave, como exige el art. 301.3.

Concatenado a este último argumento, el Tribunal Supremo se ha visto en la necesidad de establecer criterios para diferenciar el ámbito de la imprudencia grave -que, según este planteamiento, no afectaría a los particulares, se genera con ello un supuesto de atipicidad- del terreno del dolo eventual -que, en cualquier caso, vincula a la generalidad de los ciudadanos-. Tratándose de sujetos no obligados por las disposiciones administrativas, entiendo que lo ha hecho al interpretar las normas en atención a las consecuencias que derivan de optar por una u otra solución: cuando en la instancia se ha condenado por imprudencia y la acusación no ha recurrido para solicitar la condena por dolo, ha lamentado que los hechos probados no hubieran sido empleados para considerar la conducta intencional, quedando obligado a absolver aplicando elementales criterios de congruencia ${ }^{64} ;$ y cuando la defensa ha tratado de rebajar la responsabilidad del condenado a título de imprudencia grave, se ha resistido a casar la condena de instancia por dolo eventual apoyándose en la jurisprudencia acuñada por el propio Tribunal Supremo al respecto:
"puede afirmarse ese conocimiento cuando el autor ha podido representarse la posibilidad de la procedencia ilícita y actúa para ocultar o encubrir o ayudar a la persona que haya participado en la ilícita actividad, sin que deba exigirse una concreta calificación", bastando "un conocimiento genérico de la naturaleza delictiva del hecho sobre cuyos efectos se actúa, [...] un conocimiento de las circunstancias del hecho y de su significado social" ${ }^{65}$

63 STS 16/2009, de 27 de enero.

64 STS 924/2005, de 17 de junio. Ante un caso de condena a una particular por transportar grandes cantidades de dinero en metálico, detectadas en el aeropuerto de Barajas, la Sentencia casa la dictada en instancia, absuelve , y afirma que "en estos casos, las personas que aceptan esta operación necesariamente deben intuir o conocer la procedencia ilícita del dinero aunque sea de forma genérica o abstracta [....]. Nadie puede justificar seriamente que se presta a transportar cantidades de dinero, sin más detalles ni datos del que les entrega la cantidad y de la persona o grupo a la que van destinados [...]. Como no podemos empeorar la situación procesal de la recurrente, no queda más remedio que admitir que la calificación jurídica de los hechos no ha sido la correcta". También critica la benévola calificación del acusador, pero en este caso confirma el castigo por imprudencia grave ante un supuesto de compraventa masiva de divisas, y reconoce que el art. 301.3 es un delito común, vid. la STS 1746/2003, de 23 de diciembre.

65 STS 483/2007, de 4 de junio, cita las SSTS 1637/1999, de 10 de enero de 2000; 157/2003, de 5 de febrero; 1070/2003, de 22 de julio; 308/2004, de 12 de marzo; 1113/2004, de 9 de octubre; 33/2005, de 19 de enero; 1034/2005, de 14 de septiembre. En sentido muy similar, vid. la anterior STS $94 / 2006$, de 10 de febrero. 
Como atinadamente afirmó Radbruch,

"la interpretación es el resultado de un resultado: uno no se decide a favor de un medio de interpretación hasta que no ha visto el resultado a que conduce"

Sin embargo, ante esta forma de interpretar el art. 301.3, cabe pensar si en estos casos el Tribunal Supremo no perjudicará a los ciudadanos ordinarios respecto de los sujetos obligados por las normas de prevención, al apreciar dolo sobre ellos -siquiera, eventual- cuando, de existir reglas de cuidado que les fueran aplicables, tal vez podría haberse calificado su comportamiento como imprudente.

\section{El blanqueo imprudente como delito común}

Frente a la consideración del blanqueo imprudente como delito especial, existe otra línea de pensamiento -a mi juicio, más acertada- que aboga por considerar que se trata de una figura común. Como el art. 301.3 no hace referencia explícita al sujeto activo ("si los hechos se realizasen por imprudencia grave..."), parece sensato aceptar que este precepto contiene una figura que puede cometer cualquiera, toda vez que $u b i$ lex non dintinguit, nec nos distinguere debemus. A idéntica conclusión cabe llegar si interpretamos la norma en relación con los tipos dolosos que le sirven de referencia pues, si son comunes, también lo será el tipo imprudente que de ellos depende ${ }^{67}$.

Amén de una literalidad que no invita a imponer limitaciones, la interpretación conforme a bien jurídico también permite abonar la tesis del delito común. En orden a la protección del contenido material del tipo, cualquier ciudadano puede ser sometido al deber de interesarse por el origen de los bienes, motivo por el cual nadie debe quedar excluido de la obligación penal de respetar el correspondiente deber objetivo de cuidado, máxime teniendo presente que sólo se comete el delito descrito en el art. 301.3 si se incurre en un quebrantamiento de carácter grave. En tal sentido, el quebrantamiento de esa regla de cuidado debido vendrá determinado por la falta de adecuación de la conducta del sujeto al criterio de la normal inteligencia, tomado como referencia las reglas de la lógica y la experiencia ${ }^{68}$. El carácter grave de esa imprudencia que exige el art. 301.3 se predique de quien olvide todas las precauciones o, al menos, incurra en una grave infracción de las normas elementales de cuidado; a quien omita la diligencia más elemental ${ }^{69}$.

66 RADBRUCH, Gustav: Introducción a la Ciencia del Derecho, Revista de Derecho Privado, Madrid, 1930 (trad. de Recaséns Siches), p. 156.

67 Vid., entre otros, ARÁNGUEZ SÁNCHEZ, Carlos: El delito de blanqueo de capitales, Marcial Pons, Madrid, 2000, p. 284; BLANCO CORDERO, Isidoro: El delito de blanqueo(...), Op. Cit. p. 416; FABIÁN CAPARRÓS, Eduardo A.: El delito de blanqueo(...), Op. Cit. pp. 418 y 419.

68 ARÁNGUEZ SÁNCHEZ, Carlos: El delito de blanqueo de capitales, Marcial Pons, Madrid, 2000, p. 284. En concreto, este autor plantea el ejemplo del artista que recibe el pago por una de sus obras en forma de una elevada cantidad de dinero en metálico, a pesar de que cualquier persona inteligente con una mínima experiencia es consciente de que es absolutamente inusual que en el tráfico comercial de nuestros días alguien realice un pago de varias decenas de miles de euros en efectivo.

69 BLANCO CORDERO, Isidoro: El delito de blanqueo 8...), Op. Cit. pp. 417 y 418; PALMA HERRERA, José Manuel: Los delitos de blanqueo (...), Op. Cit. pp. 593 y 594. 
Comentario aparte merece una circunstancia que, afortunadamente, ya ha sido resuelta por el legislador. Hasta la incorporación a nuestro ordenamiento de la Ley 10/2010, de prevención del blanqueo de capitales y de la financiación del terrorismo, el ámbito objetivo de la regulación administrativa y penal sobre lavado de activos no era coincidente. Desde la reforma operada por la Ley Orgánica 15/2003, el art. 301 del Código Penal castiga los actos de blanqueo de bienes derivados de cualquier delito. Sin embargo, el art. 1. ${ }^{\circ}$ de la derogada Ley 19/1993, sobre determinadas medidas de prevención del blanqueo de capitales $^{70}$, reformado finalmente por la Ley 19/2003 ${ }^{71}$, sólo vinculaba a los sujetos obligados a vigilar las operaciones relacionadas con delitos castigados "con pena de prisión superior a tres años". Ante esta indeseable incoherencia, que se prolongó bajo distintas formas durante casi diecisiete años ${ }^{72}$, la solución consistente en interpretar el tipo de blanqueo imprudente del art. 301.3 como un delito especial condicionaba el referido ámbito objetivo de aplicación de este precepto penal: vigente la Ley 19/1993, sólo las personas obligadas por ella, y sólo respecto de los citados delitos antecedentes establecidos en la misma, quedaban vinculadas al cumplimiento del art. 301.3. En consecuencia -y en tanto se persista en la idea de que el blanqueo imprudente es un delito especial, insisto-, se daría la paradójica circunstancia de que, al poder perpetrarse las figuras dolosas de los arts. 301.1 y 301.2 respecto de los bienes procedentes de cualquier delito, el blanqueo imprudente del art. 301.3 sólo podría cometerse respecto de los beneficios derivados de la comisión de delitos castigados con pena de prisión superior a tres años. Apreciada incorrecta esta limitación, hubo quienes abandonaron la posibilidad de que el art. 301.3 constituyera un delito especial, y prefirieron interpretarlo como un tipo común ${ }^{73}$.

70 Ley 19/1993, de 28 de diciembre, sobre determinadas medidas de prevención del blanqueo de capitales (BOE No. 311, de 29 de diciembre, pp. 37327 y ss.).

71 Ley 19/2003, de 4 de julio, sobre régimen jurídico de los movimientos de capitales y de las transacciones económicas con el exterior y sobre determinadas medidas de prevención del blanqueo de capitales (BOE No.160, de 5 de julio, pp. 26166 y ss.).

72 Desde la vigencia de la Ley 19/1993 hasta la de la Ley 10/2010, la discordancia entre la normativa penal y la normativa administrativa ha variado. En ocasiones, la norma represiva se ha referido a menos delitos previos que la norma de preventiva -así ocurrió hasta la entrada en vigor de la versión original del Código Penal de 1995-, mientras que durante otros periodos -por ejemplo, hasta el momento en que comenzó a regir la Ley 10/2010- la relación ha sido inversa. Durante todo ese periodo, el ámbito objetivo de aplicación sólo coincidió entre la reforma de la regulación administrativa operada por la Ley 19/2003 (6 de julio de 2003) y la entrada en vigor de la modificación del Código Penal que introdujo la Ley Orgánica 15/2003 (1 de octubre de 2004), tiempo durante el cual ambas regulaciones se refirieron como infracciones previas a los delitos graves: aquellos con una pena de prisión superior a tres años.

73 Así, PALMA HERRERA, José Manuel: Los delitos de blanqueo (...), Op. Cit. p. 594 (cuando este autor defendió este argumento, la Ley 19/1993 sólo contemplaba como delitos antecedentes el tráfico de drogas, el crimen organizado y el terrorismo, mientras que el art. 301 del Código Penal, previo a la reforma operada por la Ley Orgánica 15/2003, se refería a los bienes procedentes de cualquier delito grave). Haciéndose eco de este planteamiento, vid. BLANCO CORDERO, Isidoro: El delito de blanqueo (...), Op. Cit. p. 415. 
Con todo, tras la derogación y reemplazo de la Ley 19/1993 por la nueva Ley 10/2010 -que, desde la perspectiva de la prevención, controla los movimientos de capitales procedentes de cualquier delito, del mismo modo que lo hace desde la represión el art. 301 del Código Penal-, el problema ha desaparecido y, con ello, el argumento a favor de la tesis del delito común. En la actualidad, la calificación del blanqueo imprudente como delito especial o común no condiciona el cuadro de infracciones antecedentes que atiende.

En el marco de esa jurisprudencia vacilante a la que ya me he referido, el Tribunal Supremo también ha tenido ocasión de denunciar la limitación de delitos previos a la que conducía una interpretación conjunta de la extinta Ley 19/1993 y del Código Penal $^{74}$. Superado este problema por el legislador, resulta más rentable centrarse en otros aspectos sobre los que se ha pronunciado este órgano jurisdiccional en beneficio de la tesis del delito común.

Las resoluciones dictadas hasta ahora en este sentido parten de un dato evidente: los destinatarios habituales de las penas previstas en el art. 301.3 son los profesionales que actúan en aquellos sectores económicos más utilizados por los blanqueadores; sujetos que, por lo demás, si las normas administrativas sobre prevención están bien construidas, deberán encontrarse entre el listado de sujetos obligados. Sin embargo, que esto sea cierto en el plano criminológico no significa que también lo sea en el dogmático. De hecho, la confusión entre lo fenomenológico y lo normativo -entre la normalidad y la normatividad, según terminología de $\mathrm{Heller}^{75}$ - parece caracterizar el contenido de algunas de las resoluciones del Tribunal Supremo sobre la materia, que incluso ha llegado a invocar los mismos argumentos para llegar a conclusiones contrapuestas $^{76}$. Aunque el hecho delictivo "normalmente coincidirá en sujetos o entidades cuyas actividades guarden relación con los movimientos de capitales"77,

74 SSTS 1034/2005, de 14 de septiembre; 1257/2009, de 2 de diciembre.

75 HELLER, Hermann: Teoría del Estado, Fondo de Cultura Económica, México, 1985 (11a ed.) (trad. de Tobio), p. 269.

76 Así, las SSTS 1257/2009, de 2 de diciembre; 16/2009, de 27 de enero; y 483/2007, de 4 de junio, refiriéndose a la actuación de los sujetos obligados, señalan que "el blanqueo por imprudencia reviste el carácter de delito especial, que sólo pueden cometer los destinatarios de los deberes que impone la normativa administrativa (intermediarios financieros, mediadores en las transacciones inmobiliarias, profesionales del sector bancario y otros .)". Con todo, mientras las dos últimas resoluciones se lleva el argumento hasta las últimas consecuencias, considerando que el art. 301.3 alberga un tipo especial, la primera concluye finalmente afirmando que "es un delito común, de manera que puede ser cometido por cualquier ciudadano, en la medida en que actúe con falta del cuidado socialmente exigible para evitar el daño al bien jurídico protegido".

77 STS 960/2008, de 26 de diciembre. Entre la doctrina, vid., por ejemplo, BLANCO CORDERO, Isidoro: El delito de blanqueo (...), Op. Cit. p. 416; FABIÁN CAPARRÓS, Eduardo A.: El delito de blanqueo..., Op. Cit.pp. 419 y 420; PALMA HERRERA, José Manuel: Los delitos de blanqueo (...), Op. Cit. pp. 593 y ss. 
nada impide que un ciudadano cualquiera pueda ser autor de un delito imprudente de blanqueo. De hecho, ni la mera infracción de la normativa administrativa constituye necesariamente un supuesto de blanqueo imprudente ${ }^{78}$, ni el escrupuloso cumplimiento de todas y cada una de las ellas garantiza -en tanto aceptemos la discutible conclusión a la que llegado el Tribunal Supremo en un reciente pronunciamiento- que un sujeto obligado no pueda ser condenado por este delito, dado que los deberes contenidos en las normas preventivas son eminentemente formales ${ }^{79}$.

En todo caso, el problema consistirá en determinar el deber objetivo de cuidado al que se encuentran sujetos en este ámbito con objeto de evitar el daño al bien jurídico protegido. Como ya señalé antes en relación con la tesis del delito especial, el Tribunal Supremo considera que es especialmente difícil determinar las cautelas exigibles en aquellas actividades sociales para las que no se hayan establecido expresamente normas de cuidado, o en las situaciones atípicas, determinar el cuidado objetivamente debido mediante el simple criterio de "la conducta que observaría en esa situación concreta una persona inteligente y sensata de la misma profesión o círculo social" ${ }^{\circ 0}$. Así, las resoluciones son variadas y apelan a "una mínima atención, una precaución exigible" $"$, a la "significativa dejación del cuidado y determinante abandono

78 ZARAGOZA AGUADO, Javier A.: "Receptación y blanqueo de capitales", en VV. AA.: El nuevo Código Penal y su aplicación a empresas y profesionales. Manual teórico-práctico (III), Coopers \& Lybrand, Madrid, 1996, p. 476. En el mismo sentido, BLANCO CORDERO, Isidoro: El delito de blanqueo (...), Op. Cit. p. 418; PALMA HERRERA, José Manuel: Los delitos de blanqueo (...), Op. Cit.p. 596.

79 Como señala la STS 810/2010, de 23 de septiembre, "ni siquiera el cumplimiento de las obligaciones impuestas por la Ley y el Reglamento serían criterio concluyente para excluir su eventual responsabilidad penal, pues se estaría ante un cumplimiento puramente formal realizado en la confianza de que no se iban a activar los mecanismos de persecución de la actividad supuestamente delictiva [...]. Otra cosa es que el incumplimiento de esas obligaciones administrativas sea un dato que permite apuntalar la convicción de esa responsabilidad, o sobre el que construir la negligencia". Sin duda, nos encontramos ante una afirmación cuestionable que sólo puede aceptarse en el caso de que partamos de la convicción de que el art. 301.3 integra un tipo común. Respecto de la generalidad de los ciudadanos, existiría un deber genérico de cuidado que podría vulnerarse con independencia de las normas administrativas de control; pero respecto de los sujetos obligados, la teoría de los actos neutrales nos lleva a defender que el profesional que actúa desde el estricto cumplimiento de las normas que le afecten como profesional no debe responder penalmente, incluso en el caso de que sea consciente de la ayuda que presta [vid. BLANCO CORDERO, Isidoro: Responsabilidad penal..., op. cit.; SILVA SÁNCHEZ, Jesús María: "La intervención de Notarios en la comisión de delitos patrimoniales y económicos", en PALACIOS CRIADO, María Teresa - FUENTES MARTÍNEZ, Jesús Julián (dirs.): Judicatura y Notariado..., Op. Cit.pp. 178 y 179]. De este modo, se daría la paradoja de que la presión penal derivada del art. 301.3 podría llegar a ser más intensa para los profesionales que para los particulares, lo cual carece de sentido.

80 ATS 790/2009, 16 de abril; STS 1034/2005, de 14 de septiembre. En idénticos términos, aunque luego afirmando que se trata de un delito especial, la STS 16/2009, de 27 de enero.

81 STS 1746/2003, 23 de diciembre. 
de las precauciones usuales del caso" ${ }^{\$ 2}$ o a haber obviado toda medida de precaución de modo que

"con la más mínima y elemental diligencia hubiera podido esclarecer y estar perfectamente impuesto del delictivo origen de los fondos a los que se prestó a facilitar su encubrimiento e introducción en el tráfico económico" ${ }^{\text {83. }}$.

Refiriéndose a casos concretos, se ha afirmado que

"cualquier persona con un nivel intelectivo medio es sabedora, sin necesidad de especiales conocimientos técnicos y/o especial formación académica, de que para realizar una transferencia no es preciso valerse de la cuenta corriente de un tercero, lo que hubo de despertar sus sospechas" ${ }^{84}$

o que

"el recurrente estaba en condiciones de haber conocido, con sólo observar las mínimas cautelas, el origen ilícito del dinero utilizado en la adquisición de la vivienda que se puso a su nombre y su relación con el tráfico de drogas", estimándose grave la imprudencia en la que incurrió por la "alta posibilidad que tenía de superar toda ignorancia sobre el origen de los bienes" $"$.

\section{Algunas consideraciones finales}

Como indiqué al comienzo de la exposición, el art. 301.3 del Código Penal español alberga numerosas interrogantes que aún carecen de una respuesta definitiva.

La primera de ellas afecta a su propia existencia. En el terreno de lo formal, nos encontramos ante una figura que apenas encuentra respaldo en los instrumentos internacionales y que ha sido acogida por muy pocos Estados en sus respectivos ordenamientos internos. En el ámbito de la antijuricidad material, cabe cuestionarse si se trata de una conducta que merece ser atendida por parte del ordenamiento penal o si, por el contrario, bastaría con encomendar su control a las normas de Derecho Administrativo.

En general, el juicio que ha merecido la incorporación del delito culposo de blanqueo al ordenamiento español ha sido predominantemente negativo. En su Informe al Anteproyecto de Código Penal de 1992, el Consejo General del Poder Judicial censuró su posible inclusión en el texto definitivo afirmando que

82 STS 1034/2005, de 14 de septiembre.

83 STS 960/2008, de 26 de diciembre.

84 ATS 790/2009, 16 de abril, en relación con un joven que aceptó una oferta recibida por correo electrónico para transferir a otras personas, a través de su propia cuenta y a cambio de una comisión, importantes cantidades de dinero recibidas de terceros.

85 STS 1257/2009, de 2 de diciembre, respecto de la adquisición de diversos bienes con los rendimientos derivados del narcotráfico. 
"aunque razones de política criminal puedan justificar la penalización de la imprudencia grave, no es menos cierto que tal posibilidad es dogmáticamente muy discutible" 86 .

Ya aprobado el Código de 1995, numerosos autores valoraron negativamente la existencia del art. 301.3, acusándolo de vulnerar los principios de ultima ratio y proporcionalidad ${ }^{87} \mathrm{o}$, directamente, de ser un "disparate" derivado de los excesos de la reciente política criminal, alentados por la presión de los medios de comunicación ${ }^{88}$.

Con todo, entiendo que el principal argumento para su mantenimiento no estriba en razones dogmáticas, sino en un argumento práctico tan indiscutible como cuestionable. La posibilidad de castigar supuestos de negligencia, asociada a la necesidad de respetar el principio de presunción de inocencia, permite afirmar que el art. 301.3 es un instrumento orientado a penalizar actos de blanqueo respecto de los cuales no haya sido posible probar el dolo del sujeto. Siendo así, el blanqueo imprudente se convierte en un tipo de recogida en el que no se pretende tanto castigar a quien opera sobre unos bienes cuyo origen criminal no conoció, debiendo haberlo hecho, como a quien, siendo sospechoso de haber tenido noticia de esa procedencia, no se le pudo probar. Como ya indiqué hace años, en tanto la principal dificultad ante la que se hallen las autoridades consista en demostrar que el acusado ha cumplido la vertiente subjetiva del tipo, el legislador puede decantarse por negar la mayor, esto es, prescindir de esa regulación tan incómoda cuando sea inaplicable para sustituirla por otra tipicidad cuya vertiente subjetiva sea menos exigente ${ }^{89}$. Según Pieth, la penalización del blanqueo imprudente constituye un "invento con cálculos criminalísticos" $" 90$.

Más allá de las razones a favor o en contra sobre su existencia, también cabe realizar algunos comentarios sobre su configuración típica. Según la estructura de la exposición que he realizado en el presente trabajo, me permito indicar las siguientes observaciones:

a) Para ser coherentes con el criterio de crimina culposa seguido por el codificador de 1995, sería deseable reformar el art. 301.3 con objeto de definir con claridad la conducta infractora del deber objetivo de cuidado sin necesidad de remitirse a las figuras dolosas. En consecuencia, se reclama un tipo verdaderamente autónomo que no precise apoyarse en otros tipos para su aplicación.

86 CONSEJO GENERAL DEL PODER JUDICIAL: Anteproyecto del Código Penal 1992 e Informe y votos agregados del Consejo General del Poder Judicial, Madrid, 1992, p. 246.

87 En tal sentido, vid. ABEL SOUTO, Miguel: El blanqueo de dinero, Op. Cit. pp. 179 y 180.

88 COBO DEL ROSAL, Manuel - ZABALA LÓPEZ-GÓMEZ, Carlos: Blanqueo de capitales (...), Op. Cit. pp. 101 a 103.

89 FABIÁN CAPARRÓS, Eduardo A.: El delito de blanqueo (...), Op. Cit. p. 337. En sentido similar, y entre otros, BLANCO CORDERO, Isidoro: Responsabilidad penal (...), Op. Cit. pp. 191 y 192; PALMA HERRERA, José Manuel: Los delitos de blanqueo..., Op. Cit. pp. 598 y 599.

90 Citado por BLANCO CORDERO, Isidoro: Responsabilidad pena (1..)., Op. Cit. pp. 191 y 192. 
b) Sería deseable restringir típicamente las hipótesis punibles de blanqueo imprudente al desconocimiento respecto del origen delictivo de los bienes, suprimiendo con ello la posibilidad de que la literalidad del art. 301.3 permita extender su vigencia a otros supuestos, como puede ser el error respecto de la conducta. Con ello, además, el legislador español sería más coherente con las previsiones internacionales al respecto y con el resto de países que han aprobado figuras similares.

c) Respecto del sujeto activo, de lege lata, entiendo que debe aceptarse que nos encontramos ante un delito común. Al amparo del principio de legalidad, nada impide que el castigo se extienda a cualquier ciudadano. Además, no parece demasiado consistente la idea de limitar la amenaza penal a los sujetos obligados por la Ley 10/2010, a pesar de que sea cierto que respecto de ellos sea más fácil determinar el quebrantamiento del deber objetivo de cuidado que dé lugar a un caso de imprudencia grave. A mi juicio, cabe exigir a todos los ciudadanos ciertas cautelas elementales, sin duda menos intensas que las que recaen sobre ciertos profesionales cuya actividad se encuentra específicamente regulada ${ }^{91}$, pero cuya relevancia en el marco de la sociedad de la información parece fuera de toda duda ${ }^{92}$.

d) De lege ferenda, sin embargo, considero que en esa reformulación que propongo para el art. 301.3 debería valorarse la oportunidad de configurar un tipo especial que sólo se dirija a los profesionales sometidos a las obligaciones derivadas de la normativa administrativa preventiva. Probablemente una medida como esta limite la eficacia práctica de los dispositivos penales sobre el blanqueo de capitales, dado que con ello sólo se podrá castigar a la generalidad de los ciudadanos en la medida en que se pruebe que actuaron, al menos, con dolo eventual. Por ello, cuando proceda, interesará reforzar la motivación de las resoluciones judiciales argumentando su estructura lógica de acuerdo con los criterios de prueba indiciaria, no rebasando nunca los límites establecidos por el Tribunal Constitucional y el Tribunal Europeo de Derechos Humanos. De ello resultará beneficiado el principio de intervención mínima.

e) En cualquier caso, me parece que la ausencia de un criterio unitario en la jurisprudencia respecto de la delimitación del sujeto activo del art. 301.3 exige un Acuerdo de Sala que establezca de una vez por todas--y en tanto permanezca la legalidad vigente, claro está- el criterio a seguir en futuras resoluciones.

91 LOMBARDERO EXPÓSITO, Luis Manuel: Blanqueo de capitales. Prevención y represión del fenómeno desde la perspectiva penal, mercantil, administrativa y tributaria, Bosch, Barcelona, 2009, pp. 182 y 183.

92 Baste recordar el caso enjuiciado por el ATS 790/2009, 16 de abril, en el que se confirma la Sentencia condenatoria dictada por la Audiencia Provincial de Granada sobre un "mulero" que aceptó realizar numerosas transferencias de dinero entre cuentas ajenas, con la propia como intermediaria, a cambio de una sustanciosa comisión. Sobre este caso, vid. LOMBARDERO EXPÓSITO, Luis Manuel: Blanqueo de capitales (...), Op. Cit. pp. 58 y 59. 


\section{REFERENCIAS}

Abel Souto, Miguel: El blanqueo de dinero en la normativa internacional. Especial referencia a los aspectos penales, Universidad de Santiago de Compostela, Santiago de Compostela, 1999.

Aránguez Sánchez, Carlos: El delito de blanqueo de capitales, Marcial Pons, Madrid, 2000.

Bajo Fernández, Miguel - BACIGALUPO SAGESSE, Silvina (eds.): Política criminal y blanqueo de capitales, Marcial Pons, Madrid, 2009.

Blanco Cordero, Isidoro: Responsabilidad penal de los empleados de banca por el blanqueo de capitales, Comares, Granada.

Cobo Del Rosal, Manuel - Zabala López-Gómez, Carlos: Blanqueo de capitales. Abogados, procuradores y notarios, inversores, bancarios y empresarios. (Repercusión en las leyes españolas de las nuevas directivas de la Comunidad Europea), CESEJ, Madrid, 2005.

Consejo General Del Poder Judicial: Anteproyecto del Código Penal 1992 e Informe y votos agregados del Consejo General del Poder Judicial, Madrid, 1992.

Decisión Marco del Consejo, de 26 de junio de 2001, relativa al blanqueo de capitales, la identificación, seguimiento, embargo, incautación y decomiso de los instrumentos y productos del delito (DOCE No. L 182, de 5 de julio de 2001).

Directiva 2005/60/CE, del Parlamento Europeo y del Consejo, de 26 de octubre de 2005, relativa a la prevención de la utilización del sistema financiero para el blanqueo de capitales y para la financiación de terrorismo (DOUE No. L 309, de 25 de noviembre de 2005).

Calderón Cerezo, Ángel - Saavedra Ruiz, Juan (coords.): Delitos contra el orden socioeconómico, La Ley, Madrid, 2008.

Fabián Caparrós, Eduardo A.: El delito de blanqueo de capitales, Colex, Madrid, 1998.

Gómez Iniesta, Diego J.: El delito de blanqueo de capitales en el Derecho español, Cedecs, Barcelona, 1996.

Rubio Lara, Pedro Ángel: Parte especial del Derecho penal económico español. (Una aproximación al estado de la cuestión en la Doctrina y Jurisprudencia españolas), Dykinson, Madrid, 2006.

Heller, Hermann: Teoría del Estado, Fondo de Cultura Económica, México, 1985.

Ley Orgánica 10/1995, de 23 de noviembre, del Código Penal (BOE No. 281, de 24 de noviembre, pp. 33987 y ss.).

Ley Orgánica 15/2003, de 25 de noviembre, por la que se modifica la Ley Orgánica 10/1995, de 23 de noviembre, del Código Penal (BOE No.283, de 26 de noviembre, pp. 41842 y ss.).

Ley Orgánica 5/2010, de 22 de junio, por la que se modifica la Ley Orgánica 10/1995, de 23 de noviembre, del Código Penal (BOE No.152, de 23 de junio, pp. 54811 y ss.). 
Ley 10/2010, de 28 de abril, de prevención del blanqueo de capitales y de la financiación del terrorismo (BOE No. 103, de 29 de abril, pp. 37458 y ss.).

Ley Orgánica 8/1992, de 23 de diciembre, de modificación del Código Penal y de la Ley de Enjuiciamiento Criminal en materia de tráfico de drogas (BOE No. 308, de 24 de diciembre de 1992, pp. 43861 y ss.).

López Garrido, Diego-GARCÍA ARÁN, Mercedes: El Código Penal de 1995 y la voluntad del legislador, Tirant lo Blanch, Valencia.

Lombardero Expósito, Luis Manuel: Blanqueo de capitales. Prevención y represión del fenómeno desde la perspectiva penal, mercantil, administrativa y tributaria, Bosch, Barcelona, 2009.

Palma Herrera, José Manuel: Los delitos de blanqueo de capitales, EDERSA, Madrid, 2000.

Pérez Manzano, Mercedes: "El tipo subjetivo en los delitos de receptación y blanqueo de dinero", Cuadernos de Derecho Judicial, vol. I (1995).

Quintero Olivares, Gonzalo: "Sobre la ampliación del comiso y el blanqueo, y la incidencia en la receptación civil", Revista Electrónica de Ciencia Penal y Criminología, No. 12 (2010).

Queralt Jiménez, Joan J.: "La reforma penal y procesal en materia de tráfico de drogas", Actualidad Jurídica Aranzadi, No. 96.

Ragués I Vallès, Ramón: La ignorancia deliberada en Derecho penal, Atelier, Barcelona, 2008. passim.

SSTS 28/2010, de 28 de enero; 483/2007, de 4 de junio.

SSTS 1257/2009, de 2 de diciembre; 1025/2009, de 22 de octubre; ATS 790/2009, de 16 de abril; 960/2008, de 26 de diciembre; 1034/2005, de 14 de septiembre

Vidales Rodríguez, Caty: Los delitos de receptación y legitimación de capitales en el Código Penal de 1995, Tirant lo Blanch, Valencia. 